\title{
DISTROFIA MUSCULAR PROGRESSIVA: ALGUNS ASPECTOS DO DIAGNÕSTICO DIFERENCIAL
}

\author{
Sylvio Saraiva * \\ Aron J. Diament ** \\ José Antonio Levy ***
}

Conquanto, em suas formas clássicas, não seja difícil o diagnóstico da distrofia muscular progressiva (DMP), há uma série de afecções neurológicas e metabólicas, com as quais pode haver confusão. Nesse sentido julgamos excelente o esquema de Swynyard e col. ${ }^{9}$, classificando as afecções com as quais deve ser feito o diagnóstico diferencial dessa miopatia. Além dos dados clínicos e dos exames complementares (electrodiagnóstico, electromiografia, dosagens bioquímicas) que podem ser utilizados para a diferenciação diagnóstica, tem sido salientada ${ }^{3}$ a importância da biopsia muscular e é sôbre êste aspecto que nos estenderemos mais longamente. As lesões musculares na DMP se caracterizam pela presença de fibras musculares em vários estádios de atrofia, ao lado de fibras normais; entre as fibras existe grande quantidade de células ađiposas, responsável pelo maior volume de certos músculos nas formas pseudo-hipertróficas; pode existir pequena reação celular (alguns mononucleares); não há sinais regenerativos (nucléolos proeminentes e citoplasma basófilo).

$\mathrm{Na}$ presente exposição não procuraremos estudar pormenorizadamente tôdas as doenças com as quais o diagnóstico diferencial com a DMP deve ser feito. Nosso objetivo é chamar a atenção para algumas entidades clínicas menos conhecidas e de reconhecimento mais difícil.

Atrofia muscular espinal progressiva infantil (doença de Werdnig-Hoffmann) - A moléstia inicia-se no primeiro ano de vida e manifesta-se por déficits motores proximais. Parece ser secundária a uma denervação, de modo que, na evolução, instalam-se fibrilações musculares. Pode haver comprometimento da musculatura do tronco e região cervical. Essa sintomatologia é acompanhada de amiotrofias e arreflexia profunda. A confusão com a DMP pode ser feita antes de surgirem sinais de lesão das vias motoras; o próprio Werdnig considerou inicialmente os seus casos como sendo de distrofia muscular progressiva, forma Leyden-Möbius ${ }^{4}$. Nesta fase a

Trabalho da Clínica Neurológica da Fac. Med. da Univ. de São Paulo (Prof. Adherbal Tolosa), apresentado ao Simpósio sôbre Miopatias realizado no Departamento de Neuropsiquiatria da Associação Paulista de Medicina, em 9 abril 1960.

* Assistente extranumerário. ** Assistente voluntário. *** Assistente efetivo. 
biopsia pode fornecer elementos para o diagnóstico. $O$ quadro anátomopatológico caracteriza-se pelo encontro de grupos de fibras musculares diminuídas de tamanho, entre as quais se encontram fibras musculares normais ou hipertrofiadas. Não há proliferação de colágeno endomisial. Podem ser encontrados pequenos infiltrados de linfócitos ao redor dos vasos.

Amiotonia congênitu (doençu de Oppenheim) - Não nos parece oportuno discutir aqui as relaçōes patogênicas entre as doenças de WerdnigHoffmann e de Oppenheim. Incluem-se neste último grupo crianças que apresentam, nos seis primeiros meses de vida, fraqueza com flacidez dos músculos proximais, e que ulteriormente viriam a apresentar melhoras. Êste quadro, descrito primitivamente por Oppenheim, inclui-se no grupo recentemente descrito por Walton como "hipotonia congênita benigna" ${ }^{10}$. A biopsia muscular não mostra anormalidade alguma; as fibras musculares apresentam-se pequenas, mas de acôrdo com a idade do paciente.

Poliomielite anterior aguda congênita - Deve ser lembrada esta possibilidade como causa de fraqueza e de atrofias musculares em recém-nascidos, principalmente quando a gravidez tenha coincidido com períodos epidêmicos de poliomielite anterior aguda. Naturalmente, as paralisias apresentam os caracteres próprios da poliomielite anterior aguda.

Artrogripose múltipla congênita - Caracteriza-se pela presença, desde o nascimento, de atrofias musculares mais ou menos acentuadas, associadas à limitação dos movimentos articulares. Cêrca de 300 casos já foram descritos, com incidência maior no sexo masculino. A afecção pode ser prenunciada na gravidez, pelo fato dos movimentos fetais serem pouco numerosos e de aparecimento tardio. Aos cortes histológicos, as fibras musculares se apresentam grandes, com alterações estruturais e fagocitose; ao redor dos vasos encontram-se polimorfonucleares e linfócitos; há aumento de colágeno endomisial. A patogenia da afecção não está ainda estabelecida; os dados anátomo-patológicos podem ser interpretados como decorrentes de miosite ou de uma forma de distrofia com reação inflamatória e conjuntiva. Adams e col. ${ }^{1}$ descreveram uma neuropatia com essa sintomatologia. Outros autores admitem que a lesão se localize na ponta anterior da medula (rarefação ou desaparecimento das células motoras) ${ }^{6}$.

Tesaurismose glicogênica (doença de von Gierke) - Trata-se de moléstia causada por transtôrno metabólico na infância, familial, tendo como conseqüência depósito excessivo de glicogênio em vários tecidos, determinando aumento de volume dos órgãos. O coração e o fígado são os órgãos mais atingidos. O comprometimento muscular pode determinar debilidade e hipotonia muscular. O estudo do material de biopsia muscular deve ser feito por métodos especiais para o glicogênio (carmim de Best, método de Schiff); histològicamente, verifica-se vacuolização da fibra muscular; podem ser encontradas fibras musculares aumentadas de volume. 
"Central core disease" — Shy e Magee ${ }^{8}$ descreveram recentemente 5 casos em três gerações de uma família, caracterizados por fraqueza muscular desde o nascimento, com hipotonia e conservação dos reflexos profundos, sem pioras. O quadro anátomo-patológico é característico: ao corte transversal encontra-se, no centro das fibras, um grupo de miofibrilas mais amorfas que as circunvizinhas; pelo método de Gomori essas miofibrilas adquirem coloração azul. Essa a origem da denominação da moléstia dada pelcs autores; seria uma doença do "âmago central" da fibra muscular.

Colagenoses (dermatomiosite e polimiosite crônicas) - Geralmente iniciam-se com sintomatologia prodrômica, inexistente na DMP: febre, emagrecimento, dôres musculares e fatigabilidade. A fraqueza muscular em geral é proximal, bilateral e simétrica, como na distrofia muscular progressiva. Pode haver comprometimento de músculos oculares e velofaríngeos, com disfagia. A biopsia muscular evidencia edema intersticial com dissociação das fibras musculares, além de infiltração linfocitária; há também edema e atrofia das fibras musculares?

Miopatia tireotóxica crônica - Clinicamente caracteriza-se por fraqueza e atrofias musculares, sendo mais gravemente atingidas as cinturas escapular e pélvica. Os pacientes podem queixar-se inicialmente de dificuldades para subir escadas. Os sintomas musculares podem aparecer antes das manifestações tireotóxicas ${ }^{1}$. $\mathrm{O}$ estudo anátomo-patológico demonstra tratar-se de uma lipomatose, de modo que a biopsia muscular evidenciará cẻlulas gordurosas entre os feixes musculares; verifica-se também atrofia das fibras musculares.

Distrofia muscular da menopausa - Foi descrita por Shy e McEachern ?. A moléstia se iniciaria após os 40 anos, caracterizando-se por fraqueza muscular, que atinge predominantemente as cinturas. Os reflexos profundos estão presentes ou diminuídos. Corresponderia à miopatia progressiva tardia, descrita anteriormente por Nevin ${ }^{5}$. O quadro anátomo-patológico é de necrose e degeneração focal das fibras musculares, formando-se placas necróticas; a reação intersticial é pequena. Os casos relatados apresentaram melhoras com cortisona.

\section{SUMMARY}

Progressive muscular dystrophy: some aspects of differential diagnosis.

The authors call attention to some clinical entities which are less known and more difficult to recognize and with which differential diagnosis of progressive muscular dystrophy should be made (infantile spinal muscular atrophy, amyotonia congenita, congenital acute anterior poliomyelitis, anthrogriposis multiplex, von Gierke's disease, central core disease, chronical polymyositis and dermatomyositis, thyrotoxic myopathy and menopausal dys- 
trophy). The importance of muscle biopsy in the differential diagnosis is emphasized.

\section{REFERENCIAS}

1. ADAMS, R. D.; DENNY-BROWN, D.; PEARSON, C. M. - Enfermedades del Músculo. Trad. castelhana. La Fragua, Buenos Aires, 1957. 2. GARCIN, R.; LAPRESLE, J.; GRUNER, J.; ICHERRER, J. - Les polymyosites. Rev. Neurol., 92: 465-510, 1955. 3. GREENFIELD, J. G.; CORNMAN, T.; SHY, M. G. - The prognostic value of the muscle biopsy in the "floppy infant". Brain, 81:461-484, 1958. 4. MELARAGNO, R. - Contribuição para o estudo das amiotrofias espinhais familiais infantis. Tese, São Paulo, 1952. 5. NEVIN, S. - Two cases of muscular degeneration occurring in late adult life with a review of the recorded cases of late muscular dystrophy (late progressive myopathy). Quart. J. Med., 5:51-68, 1936. 6. RAVERDY, P. - Arthrogripose multiple congénitale. Encycl. Méd.-Chir., sect. Neurologie, 17181, 1-1959. 7. SHY, M. G.; MCEACHERN, D. - The clinical features and response to cortisone of menopausal muscular distrophy. J. Neurol. Neurosurg. Psychiat., 14: 101-107, 1951. 8. SHY, M. G.; MAGEE, K. R. - A new congenital non progressive myopathy. Brain, 79:610-621, 1956. 9. SWYNYARD, C. A.; DEAVER, G. G.; GREENSPAN, L. - Progressive muscular dystrophy: diagnosis and problems of rehabilitation. Muscular Dystrophy Associations of America Inc., Nova York, 1958. 10. WALTON, J. N. - Amyotonia congenita: a follow-up study. Lancet, 270:1023-1028 (junho, 30) 1956.

Clínica Neurológica - Hospital das Clinicas da Fac. Med. da Univ. de São Paulo - Caixa Postal 3461 - São Paulo, Brasil. 